\title{
Digestibilidade e balanço de nitrogênio de rações com diferentes teores de proteína degradável no rúmen e milho moído como fonte de amido em ovinos
}

\section{Lúcia Maria Zeoula1, Fernanda Fereli², Ivanor Nunes do Prado1, Luiz Juliano Valério Geron ${ }^{3}$, Saul Ferreira Caldas Neto ${ }^{4}$, Odimari Pricila Pires do Prado ${ }^{2}$, Emilyn Midori Maeda ${ }^{3}$}

\footnotetext{
1 Universidade Estadual de Maringá - PR, Av. Colombo, 5790, CEP 87020-900, Bolsista do CNPq.

2 Mestrando em Produção Animal pela Universidade estadual de Maringá -UEM.

${ }^{3}$ Doutorando em Produção Animal pela Universidade Estadual de Maringá (UEM) - PR, Bolsista do CNPq

${ }^{4}$ Centro de Ensino Superior de Maringá (Cesumar) - PR.
}

RESUMO - O objetivo neste trabalho foi avaliar a digestibilidade aparente de rações com diferentes teores de proteína degradável no rúmen (PDR) e fonte de amido de baixa degradabilidade ruminal (milho moído) em ovinos. Utilizaram-se quatro ovinos castrados, sem raça definida (SRD), com peso vivo médio de $38,5 \mathrm{~kg}$, em um delineamento experimental quadrado latino $4 \times 4$. As quatro rações experimentais utilizadas foram compostas de $75 \%$ de volumoso (feno de aveia) e $25 \%$ de concentrado à base de milho moído (MM), farelo de soja (FS), farelo de algodão (FA), farinha de peixe (FP), uréia e sal mineral, compostas com quatro teores de PDR (46, 50, 54 e 58\% de PDR nas rações). Determinaram-se a digestibilidade aparente total dos nutrientes e o balanço de nitrogênio nos animais alimentados com as rações experimentais. Os consumos de MS, MO, PB, amido, FDN e FDA não diferiram entre as rações testadas. Da mesma forma, o nitrogênio ingerido (NI), o $\mathrm{N}$ excretado nas fezes e na urina, em g/dia, o balanço de nitrogênio (\%NI) e os coeficientes de digestibilidade da MS, MO, PB, FDN e FDA não diferiram entre as rações experimentais, sendo estimados valores médios de 31,68; 6,34; 11,31 g/dia e 44,27\% NI, respectivamente, e de 71,90; 73,$00 ; 79,70 ; 61,10 ;$ e 52,00\%, respectivamente. Independentemente dos teores de PDR em rações contendo milho como fonte de amido de baixa degradabilidade ruminal, não houve efeitos sobre a digestibilidade aparente dos nutrientes e o balanço de nitrogênio em ovinos.

Palavras-chave: coleta total, milho, retenção de nitrogênio, proteína degradável no rúmen

\section{Digestibility and nitrogen balance of sheep diets containing different levels of ruminal degradable protein and ground corn}

\begin{abstract}
Four castrated sheep averaging $38.5 \mathrm{~kg}$ of body weight were randomly assigned to a $4 \mathrm{x} 4$ Latin square to evaluate the apparent digestibility of nutrients and nitrogen balance (NB) on diets containing different levels of rumen degradable protein (RDP): 46, 50, 54, and $58 \%$ and ground corn. The four experimental diets were composed by $75 \%$ of forage (oat hay) and $25 \%$ of concentrate containing ground corn (GC), soybean meal (SM), cottonseed meal (CM), fish meal (FM), urea, and mineral salt. No significant differences were observed on the intakes of DM, OM, CP, starch, NDF, and ADF by increasing the dietary RDP levels. Nitrogen intake (NI), urinary N excretion, fecal N excretion, and NB expressed as \% NI averaged, respectively, $31.68 \mathrm{~g} / \mathrm{d}, 6.34 \mathrm{~g} / \mathrm{d}, 11.31 \mathrm{~g} / \mathrm{d}$, and $47.27 \%$ and did not differ across diets. Similarly, apparent total tract digestibilities of DM, OM CP, NDF, and ADF averaged, respectively, 71.90, 73.00, 79.70, 61.10, and 52.00\% and did not differ when the RDP level was increased in the diet. It can be concluded that both digestibility of nutrients and NB were not affected by different dietary RDP levels under the conditions of this trial.
\end{abstract}

Key Words: corn, nitrogen retention, total collection, rumen degradable protein

\section{Introdução}

As fontes de amido mais comumente utilizadas na nutrição animal são os grãos de cereais como milho, cevada, sorgo e trigo. Todavia, os grãos de cereais, as raízes e os subprodutos agroindustriais variam amplamente quanto à disponibilidade ruminal de seus nutrientes.
O amido representa 70 a $80 \%$ dos grãos de cereais e pode ser encontrado em algumas raízes e tubérculos. Em animais ruminantes, o rúmen é o principal local de fermentação do amido presente nos grânulos da maioria dessas fontes. Os polímeros de glicose: amilose e a amilopectina que constituem os grânulos de amido são, em parte, responsáveis pelas diferentes taxas de digestão do amido (Van 
Soest, 1994). De acordo com Zeoula et al. (1999), a degradabilidade ruminal efetiva do amido do milho $(57,8 \%)$ é inferior à da raspa de mandioca $(79,1 \%)$ e do triticale $(98,4 \%)$. Martins et al. (1999) classificaram o milho moído como alimento de lenta degradação ruminal e a raspa de mandioca como de rápida degradação ruminal da MS.

A velocidade de degradação ruminal, produzida pela ação microbiana, sobre as diferentes frações dos alimentos tem ação sobre a dinâmica e o equilíbrio dos fluxos de substratos disponíveis para os microrganismos do rúmen (McCarthy et al., 1989). Casper \& Schingoethe (1989) concluíram que, variando a fonte e a degradabilidade dos carboidratos não-estruturais nas rações, pode-se otimizar a síntese de proteína microbiana no rúmen e a eficiência de utilização de proteína não-degradável no rúmen.

Em extensa revisão, Zeoula \& Caldas Neto (2001) observaram que, em muitas pesquisas, os objetivos específicos foram determinar o efeito da sincronização na suplementação da proteína e energia sobre a síntese microbiana e a produção e composição de leite. Entretanto, os resultados sobre essas variáveis foram contraditórios quando as dietas foram sincronizadas para lenta ou rápida degradação ruminal. De modo geral, as rações diferenciaram quanto à composição de ingredientes, que, por apresentar diferentes taxas de degradação, podem causar diferenças entre tratamentos em relação às quantidades de energia e nitrogênio liberados no rúmen, causando confundimento entre o grau de sincronização e outros efeitos no rúmen inerentes a um ingrediente específico.

Alguns pesquisadores (Caldas Neto et al., 2002; Caldas Neto, 2004; Prado et al., 2004) avaliaram a disponibilidade de $\mathrm{N}$ liberado no rúmen com fontes de amido de baixa (milho moído) e alta (farinha de varredura de mandioca) degradabilidade ruminal. Nos estudos sobre a digestibilidade in vitro da MS, os resultados indicaram a existência de um grau de sincronização entre os teores de PDR e a fonte de amido de alta degradabilidade ruminal, o que não ocorreu para fonte de amido de baixa degradabilidade ruminal (Caldas Neto et al., 2002). Entretanto, não foi encontrada diferença nas digestibilidades total e parcial de nutrientes e nitrogênio amoniacal no líquido ruminal em bovinos alimentados com fonte de amido de alta degradabilidade ruminal e diferentes teores de PDR (Caldas Neto, 2004). Todavia, em ovinos, foi observado aumento na digestibilidade aparente da MS quando teores crescentes de PDR foram associados à fonte de amido de alta degradabilidade ruminal, como observado por Prado et al. (2004).

Os resultados parecem indicar que, para os teores de PDR variando de 47 a $70 \%$ em associação ao milho moído, a energia disponibilizada parece ser limitante. Por outro lado, quando foi utilizada farinha de varredura de mandioca, a energia mais rapidamente disponível parece ter sido su ficiente para propiciar sincronização com o N liberado, resultando em aumentos na digestibilidade da MS e aumento de $21 \%$ na retenção de $\mathrm{N}$ em ovinos.

Nessa linha de pesquisa, este trabalho foi conduzido objetivando-se avaliar os efeitos dos teores de PDR de rações $(46,50,54$ e 58\%) com fonte de amido de baixa degradabilidade ruminal (milho) sobre a digestibilidade aparente dos nutrientes e o balanço de $\mathrm{N}$ em ovinos.

\section{Material e Métodos}

O experimento foi realizado na Fazenda Experimental de Iguatemi (FEI), no Setor de Digestibilidade para Ruminantes e no Laboratório de Análise de Alimentos e Nutrição Animal, pertencentes ao Departamento de Zootecnia (DZO) da Universidade Estadual de Maringá.

Quatro ovinos castrados, sem raça definida, com peso vivo médio de $38,5 \mathrm{~kg}$, foram utilizados em um ensaio de digestibilidade adotando-se o método de coleta total de fezes. Os animais foram alojados em gaiolas para estudos de metabolismo, com comedouro e bebedouro de aço galvanizado e dispositivo, do mesmo material, para coleta de urina. O piso da gaiola era de madeira ripada com vão de $1,0 \mathrm{~cm}$ entre ripas.

Na composição das rações experimentais (Tabela 1), foram utilizados milho (M), farelo de soja (FS), farelo de algodão (FA), farinha de peixe (FP), uréia e feno de aveia (FE). As rações foram compostas de 75,0\% de feno de aveia e $25,0 \%$ de concentrado, cuja composição percentual e química está demonstrada na Tabela 2.

Como fonte energética, utilizou-se o milho, por sua baixa degradabilidade ruminal do amido, e, como fonte de proteína, empregou-se a farinha de peixe, por sua menor degradabilidade no rúmen, seu valor biológico adequado e para proporcionar os diferentes teores de PDR utilizados nas rações experimentais.

As rações foram balanceadas de acordo com o NRC (1985) para apresentar 14,0\% de PB e 70,0\% de NDT. Diariamente, os animais receberam sal mineral $(10 \mathrm{~g}) \mathrm{e}$, duas vezes ao dia (8 e 16h) durante o período de adaptação (14 dias) receberam ração à vontade, em quantidade calculada para permitir 10,0\% de sobras, para estimativa do consumo voluntário.

Durante o período de coleta (sete dias), foram fornecidas quantidades de ração equivalentes a $90 \%$ do consumo voluntário para evitar sobras, diminuir as variações no consumo de MS e impossibilitar alterações 
Tabela 1 - Composição química dos alimentos

Table 1 - Chemical composition of the feeds

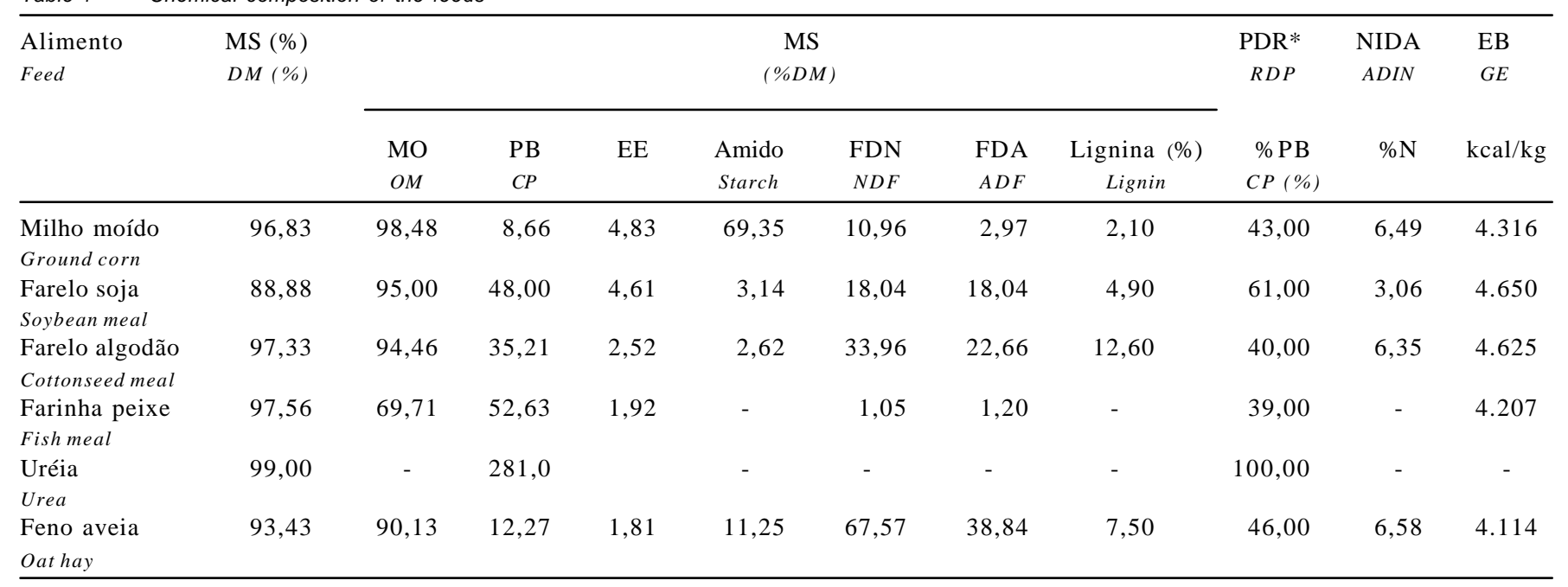

${ }^{*} \mathrm{PDR}=$ Os valores de PDR foram obtidos pelo método in situ

${ }^{*} R D P=R D P$ values were obtained by the in situ method.

Tabela 2 - Composição das rações experimentais (\% MS) Table 2 - Composition of the experimental diets (\% DM)

\begin{tabular}{|c|c|c|c|c|}
\hline \multirow[t]{2}{*}{$\begin{array}{l}\text { Alimento } \\
\text { Feed }\end{array}$} & \multicolumn{4}{|c|}{$\begin{array}{c}\text { Teor de PDR }(\%) \text { nas rações } \\
\text { Dietary RDP level }(\%)\end{array}$} \\
\hline & 46 & 50 & 54 & 58 \\
\hline $\begin{array}{l}\text { Milho } \\
\text { Ground corn }\end{array}$ & 17,35 & 17,37 & 19,92 & 20,90 \\
\hline $\begin{array}{l}\text { Farelo de soja } \\
\text { Soybean meal }\end{array}$ & 3,30 & 2,34 & 1,44 & 3,01 \\
\hline Farelo de algodão & - & 4,95 & 2,86 & - \\
\hline $\begin{array}{l}\text { Cottonseed meal } \\
\text { Farinha de peixe } \\
\text { Fish meal }\end{array}$ & 4,25 & - & - & - \\
\hline $\begin{array}{l}\text { Uréia } \\
\text { Urea }\end{array}$ & 0,10 & 0,34 & 0,78 & 1,10 \\
\hline Feno de aveia & 75,00 & 75,00 & 75,00 & 75,00 \\
\hline $\begin{array}{l}\text { Oathay } \\
\text { Total }\end{array}$ & 100,00 & 100,00 & 100,00 & 100,00 \\
\hline \multicolumn{5}{|l|}{$\begin{array}{l}\text { Composição química } \\
\text { Chemical composition }\end{array}$} \\
\hline $\begin{array}{l}\text { MS (\%) } \\
D M(\%)\end{array}$ & 94,06 & 94,61 & 94,21 & 94,07 \\
\hline $\begin{array}{l}\text { MO (\% MS }) \\
O M(\% D M)\end{array}$ & 90,04 & 91,98 & 91,29 & 91,03 \\
\hline PB (\% MS) & 14,80 & 14,50 & 14,47 & 15,00 \\
\hline $\begin{array}{l}C P(\% D M) \\
\text { Amido (\% MS) } \\
\text { Starch (\% DM) }\end{array}$ & 15,66 & 16,04 & 17,00 & 17,38 \\
\hline $\begin{array}{l}\text { FDN }(\% \text { MS }) \\
N D F(\% D M)\end{array}$ & 53,13 & 54,68 & 53,93 & 53,43 \\
\hline $\begin{array}{l}\text { FDA (\% MS) } \\
A D F(\% D M)\end{array}$ & 29,91 & 31,03 & 30,48 & 30,00 \\
\hline $\begin{array}{l}\text { PDR (\%) RDP (\%) } \\
\text { EB (Mcal/kg MS) }\end{array}$ & $\begin{array}{r}47,29 \\
4,12\end{array}$ & $\begin{array}{r}49,72 \\
4,18\end{array}$ & $\begin{array}{r}53,91 \\
4,14\end{array}$ & $\begin{array}{r}57,73 \\
4,12\end{array}$ \\
\hline $\begin{array}{l}G E(\text { Mcal } / \mathrm{kg} D M) \\
\operatorname{NDT}(\% \mathrm{MS})^{*} \\
T D N(\% D M)^{*}\end{array}$ & 68,37 & 71,50 & 68,91 & 70,52 \\
\hline
\end{tabular}

PDR = Proteína degradável no rúmen $(\% \mathrm{~PB})(R D P=$ ruminal degradable protein - \% CP).

NDT = nutrientes digestíveis totais calculado a partir da energia digestível (ED) (TDN = total digestible nutrient calculated using digestible energy (DE). nos teores de PDR propostos. Durante este período, foi realizada coleta de fezes, urina, de alimento fornecido e, eventualmente, das sobras, quando presentes. Nos períodos de adaptação e coleta, o manejo foi realizado conforme descrito por Silva \& Leão (1979).

Em cada animal, foi adaptada uma sacola de napa para coleta total de fezes, as quais foram pesadas diariamente pela manhã e homogeneizadas, sendo retiradas amostras compostas, correspondentes a $10 \%$ de seu peso total. As amostras foram acondicionadas em sacos plásticos, identificadas por animal e período experimental e armazenadas em freezer com temperatura a $-10^{\circ} \mathrm{C}$, para posterior análise. Do mesmo modo, os processos de amostragem, identificação, acondicionamento e armazenagem das amostras compostas das fezes foram realizados também para as sobras e os alimentos fornecidos aos animais (feno de aveia e concentrado).

Para a coleta de urina, foram utilizados baldes plásticos cobertos com telas, para evitar contaminação com pêlos, ração e fezes. A cada balde foram adicionados $20 \mathrm{~mL}$ de $\mathrm{HCl}$ (1:1) para evitar a volatilização de $\mathrm{N}$ e possível fermentação. A coleta de urina foi realizada sempre no mesmo horário, pela manhã, e diariamente, o volume total foi medido. Amostras de 10\% do total foram acondicionadas em um único frasco de vidro, devidamente identificado por animal, em cada período experimental (amostra composta). Os frascos foram armazenados em geladeira a aproximadamente $5^{\circ} \mathrm{C}$, para posterior análise.

As amostras foram pré-secas em estufa de ventilação forçada com temperatura controlada $\left(50 \mathrm{a} 55^{\circ} \mathrm{C}\right) \mathrm{e}$, posteriormente, foram processadas em moinho contendo peneira 
com crivo 1,0 $\mathrm{mm}$, sendo acondicionadas em vidros, que foram hermeticamente fechados e identificados.

Nas amostras dos alimentos fornecidos, das sobras e das fezes, foram determinados os teores de MS, MO, PB, amido, FDN, FDA e EB. O teor de N na urina foi calculado pelo método Kjeldahl, descrito por Silva \& Queiroz(2002), e o balanço de N (BN) foi obtido utilizando-se a fórmula: $\mathrm{BN}=\mathrm{N}$ ingerido $(\mathrm{g})-\mathrm{N}$ nas fezes $(\mathrm{g})-\mathrm{N}$ na urina $(\mathrm{g})$.

Os teores de MS, MO, PB e EB foram determinados segundo recomendações da AOAC, descritas por Silva \& Queiroz (2002), e os FDN e FDA, de acordo com a metodologia descrita por Van Soest et al. (1991). A estimativa do teor de amido foi feita pelo método enzimático, descrito por Poore et al. (1993).

Os valores de energia digestível (ED) foram obtidos a partir do coeficiente de digestibilidade da EB e os nutrientes digestíveis totais (NDT), a partir da ED, utilizando-se a seguinte fórmula de conversão: $\mathrm{ED}(\mathrm{kcal} / \mathrm{kg})$ $=(\mathrm{NDT} / 100) \times 4,409$.

O delineamento experimental foi o quadrado latino $4 \times 4$, composto de quatro animais, quatro períodos e quatro teores de PDR. As análises estatísticas das variáveis estudadas foram interpretadas por análises de variância e regressão, utilizando-se o Sistema de Análises Estatísticas e Genéticas (UFV, 1997), conforme o modelo:

$$
\mathrm{Y}_{i j k}=\mu+\mathrm{N}_{i}+\mathrm{P} j+\mathrm{A}_{\mathrm{k}}+\mathrm{e} i j k
$$

em que: $\mathrm{Y}_{i j k}=$ coeficientes de digestibilidade da variável estudada no indivíduo $k$, do período $j$, recebendo a ração com teor $i$ de 46, 50, 54 e 58\% de PDR nas rações; $\mu=$ constante geral da variável; $\mathrm{N}_{i}=$ efeito do teor $i(46,50$, 54 e $58 \%$ de PDR nas rações); $\mathrm{P} j=$ efeito do período $j$; $\mathrm{A}_{\mathrm{k}}=$ efeito do animal $\mathrm{k} ; \mathrm{e} \mathrm{e}_{i j k}=$ erro aleatório associado a cada observação $\mathrm{Y}_{i j k}$.

\section{Resultados e Discussão}

As médias de consumo de MS, MO, PB, amido, FDN, FDA, EB e ED encontram-se na Tabela 3 . O consumo de MS não foi influenciado $(\mathrm{P}>0,05)$ pelos teores de PDR nas rações, observando-se médias de $1.237,6 \mathrm{~g} / \mathrm{dia}$ e $3,1 \%$ PV. A ausência de diferença para o consumo de MS está relacionada às condições impostas no período de coleta. O consumo foi restrito para evitar os efeitos do consumo sobre os coeficientes de digestibilidade e para manter os teores de PDR propostos inicialmente, favorecendo a comparação dos resultados. Os alimentos que poderiam afetar o consumo foram utilizados dentro dos limites recomendados para os animais, como a farinha de peixe e a uréia.
Da mesma forma, Prado et al. (2004) não encontraram diferença para o consumo de MS em ovinos alimentados com teores de PDR nas rações dentro da mesma faixa proposta neste trabalho $(47,52,57$ e $62 \%)$ e tendo como concentrado energético farinha de varredura de mandioca, fonte de amido de alta degradabilidade ruminal.

Os consumos de MO, PB, amido, FDN, FDA e EB também não foram influenciados $(\mathrm{P}>0,05)$ pelos teores de PDR das rações. Prado et al. (2004) também não observaram efeito dos teores de PDR sobre o consumo de MO, PB e FDN. Como não houve efeito dos teores de PDR sobre o consumo de MS, a ausência de diferença no consumo dos demais nutrientes pode ter sido ocasionada pelo teores semelhantes destes nutrientes na MS das rações experimentais (Tabela 3 ).

Os coeficientes de digestibilidade aparente (CDA) de MS, MO, PB, amido, FDN, FDA e EB obtidos para as rações podem ser observados na Tabela 4 . A digestibilidade da MS não diferiu (média 71,9\%) com o aumento dos teores de PDR.

Araújo et al. (1995) também não observaram diferença no coeficiente de digestibilidade aparente da MS entre as dietas experimentais ao utilizarem fonte de amido de alta degradabilidade ruminal (farinha de trigo, fubá de milho e raspa de mandioca) e teores crescentes de PDR em rações para vacas leiteiras. Do mesmo modo, Caldas Neto (2004) não encontrou diferença para os CDA da MS em bovinos alimentados com teores de PDR de 55 para $70 \%$ e fonte de amido de alta degradabilidade ruminal (farinha de varredura de mandioca).

Prado et al. (2004), no entanto, observaram efeito linear crescente para o CDA da MS, que variou de 66,3 a 69,9\% em ovinos alimentados com rações com teores crescentes de PDR e fonte de amido de alta degradabilidade ruminal (farinha de varredura de mandioca). Embora o incremento no teor de PDR das rações possa aumentar a digestibilidade da MS sem que ocorra, necessariamente, aumento na atividade microbiana, é provável que, quando a disponibilidade de PDR é aumentada na presença de uma fonte de amido de alta degradabilidade ruminal, como a farinha de varredura de mandioca, a energia mais rapidamente disponível seja suficiente para propiciar sincronização com o N liberado, ocasionando aumento na digestibilidade da MS. O contrário pode ter ocorrido neste trabalho, no qual a energia pode ter sido limitante, uma vez que o incremento no teor de PDR não foi suficiente para sincronizar com a energia disponibilizada pela fonte de amido (milho) e não alterou a digestibilidade da MS.

Fu et al. (2001) utilizaram cultura de fluxo contínuo e avaliaram o efeito do incremento do teor de PDR (de 3,5 a 
Tabela 3 - Médias, equações de regressão e coeficientes de variação (CV) obtidos para os consumos diários de nutrientes em ovinos almentados com rações contendo diferentes teores de PDR

Table 3 - Means, regression equations and coefficient of variation (CV) obtained for the daily feed intake of nutrients on sheep fed diets with different RDP levels

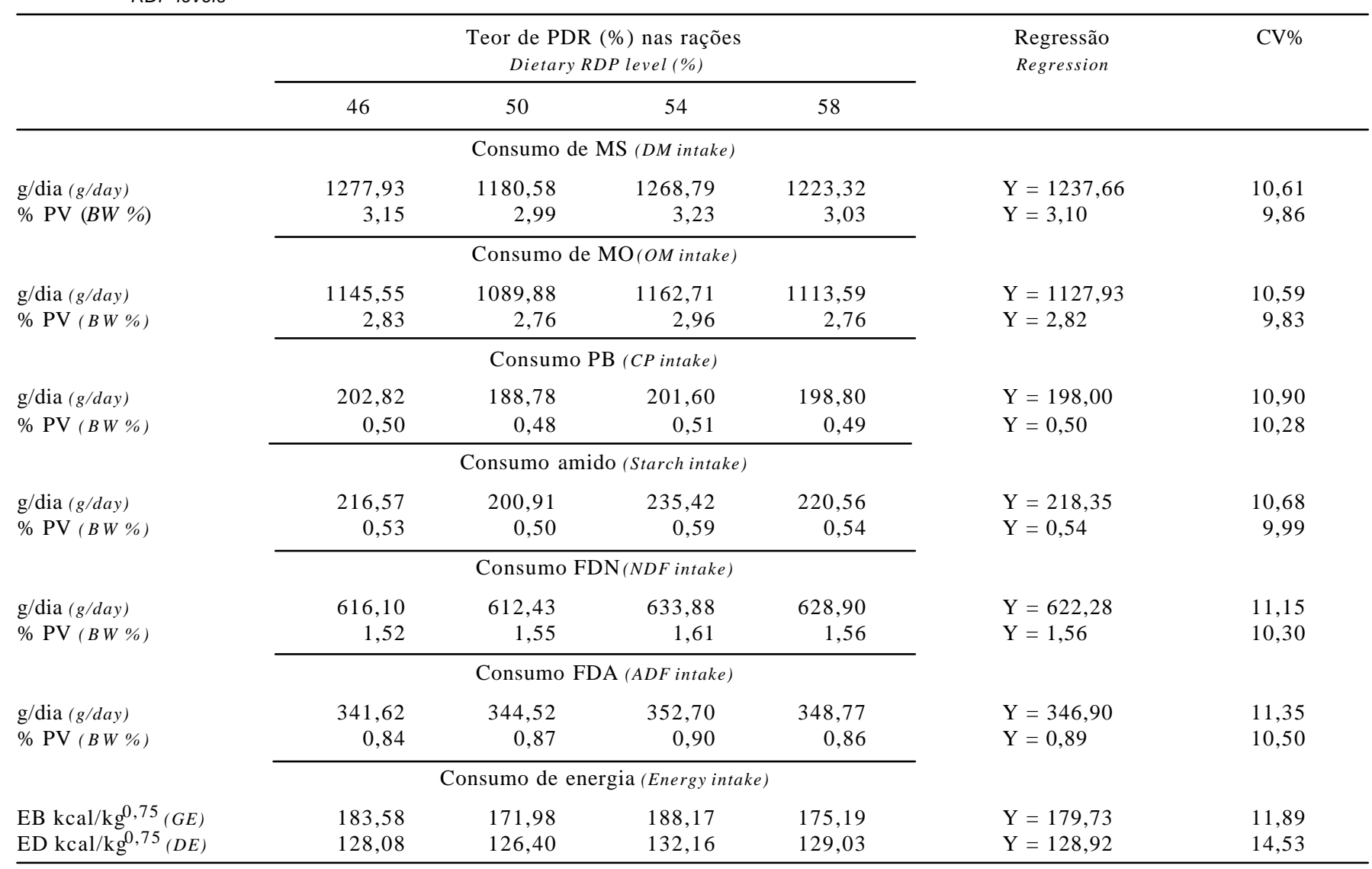

PDR = proteína degradável no rúmen; $\mathrm{EB}=$ energia bruta; $\mathrm{ED}=$ energia digestível.

$R D P=$ ruminal degradable protein; $G E$ = gross energy; $D E$ = digestible energy .

$17,5 \%$ da MS) sobre a digestibilidade da MS e a síntese microbiana em dietas contendo milho como fonte energética. Estes autores também não observaram efeito dos teores de PDR sobre a digestibilidade da MS e MO e a eficiência de síntese microbiana e concluíram que os microrganismos fermentadores de carboidratos não-estruturais tiveram suas exigências de $\mathrm{N}$ atendidas em todos os teores de PDR.

Do mesmo modo, Caldas Neto et al. (2002) avaliaram o efeito dos teores de PDR (47, 52, 57 e 62\% de PDR) em rações com fontes de amido de alta (farinha de varredura de mandioca) e baixa (milho) degradabilidade ruminal sobre a cigtibilidedìn vitro da MS (DIVMS) e não observaram efeito do teor de PDR para as rações com milho, cujo valor médio foi de $61,3 \%$ para DIVMS. Entretanto, para as rações com farinha de varredura de mandioca, foi observado efeito quadrático para o teor de PDR sobre a DIVMS e a derivada da curva indicou maior digestibilidade da MS para o teor de $60,6 \%$ de PDR. Os autores concluíram que, para as rações contendo milho como fonte energética, a energia foi insuficiente para aumentar a fermentação ruminal e não ocasionou deficiência de $\mathrm{N}$ mesmo nos menores teores de PDR. Todavia, para as rações com farinha de varredura de mandioca, a quantidade de energia foi suficiente para tornar o N limitante nos teores de PDR mais baixos, de modo que o efeito quadrático pode indicar a ocorrência de um efeito de sincronização entre a disponibilidade de $\mathrm{N}$ e energia.

Os coeficiente de digestibilidade de MO, PB, amido, FDN, FDA e EB não diferiram $(\mathrm{P}>0,05)$ entre os teores de PDR, sendo os valores médios de 73,0; 79,7; 98,5; 61,1; 52,0 e 73,7\%, respectivamente. Prado et al. (2004) observaram CDA semelhante para MO $(70,6 \%)$, maior para PB $(86,5 \%)$ e menor para FDN $(55,0 \%)$ e EB $(69,1 \%)$ em ovinos alimentados com rações com diferentes teores de PDR e farinha de varredura de mandioca. Comparando os dados de Prado et al. (2004) aos obtidos neste trabalho, sugere-se que a fonte de amido de alta degradabilidade ruminal propiciou melhor metabolismo de $\mathrm{N}$, que refletiu em maior CDA da $\mathrm{PB}$ e maior balanço de nitrogênio. Também, ao fornecer fonte de amido de alta degradabilidade ruminal e diferentes teores de PDR para bovinos, Caldas Neto (2004) observou efeito linear 
Tabela 4 - Médias, equações de regressão e coeficientes de variação (CV) obtidos para os coeficientes de digestibilidade aparente dos nutrientes em ovinos alimentados com rações contendo diferentes teores de PDR

Table 4 - Means, regression equations and coefficient of variation (CV) obtained for the apparent total tract digestibility of nutrients on sheep fed diets with different RDP levels

\begin{tabular}{|c|c|c|c|c|c|c|}
\hline \multirow[t]{2}{*}{$\begin{array}{l}\text { Nutriente } \\
\text { Item }\end{array}$} & \multicolumn{4}{|c|}{$\begin{array}{c}\text { Teor de PDR }(\%) \text { nas rações } \\
\text { Dietary RDP level }(\%)\end{array}$} & \multirow[t]{2}{*}{$\begin{array}{l}\text { Regressão } \\
\text { Regression }\end{array}$} & \multirow[t]{2}{*}{ CV\% } \\
\hline & 46 & 50 & 54 & 58 & & \\
\hline $\operatorname{MS}(\%)(D M, \%)$ & 70,7 & 73,0 & 71,3 & 72,7 & $Y=71,9$ & 5,22 \\
\hline $\mathrm{MO}(\%)(O M, \%)$ & 71,3 & 75,0 & 72,2 & 73,5 & $\mathrm{Y}=73,0$ & 4,66 \\
\hline PB $(\%)(C P, \%)$ & 77,8 & 80,6 & 78,5 & 81,7 & $Y=79,7$ & 3,56 \\
\hline Amido (\%) (Starch, \%) & 98,4 & 98,9 & 98,6 & 98,1 & $\mathrm{Y}=98,5$ & 1,17 \\
\hline FDN $(\%)(N D F, \%)$ & 57,6 & 64,3 & 59,6 & 62,8 & $\mathrm{Y}=61,1$ & 10,89 \\
\hline FDA $(\%)(A D F, \%)$ & 47,4 & 56,0 & 51,0 & 54,7 & $Y=52,0$ & 12,88 \\
\hline $\mathrm{EB}(\%)(G E, \%)$ & 73,0 & 74,5 & 72,7 & 74,7 & $\mathrm{Y}=73,7$ & 15,06 \\
\hline
\end{tabular}

Tabela 5 - Médias, equações de regressão e coeficientes de variação (CV) obtidos para a ingestão de nitrogênio (N) e excreção fecal e urinária e BN, em g/dia e \% de NI, em ovinos alimentados com rações contendo diferentes teores de PDR

Table 5 - Means, regression equations and coefficient of variation (CV) obtained for the intake of nitrogen (NI), fecal and urinary $\mathrm{N}$ excretion, and $\mathrm{N}$ balance (NB) in g/day and as a percentage of NI on sheep fed diets with different RDP levels

\begin{tabular}{|c|c|c|c|c|c|c|}
\hline \multirow[t]{2}{*}{$\begin{array}{l}\text { Nutriente } \\
\text { Item }\end{array}$} & \multicolumn{4}{|c|}{$\begin{array}{c}\text { Teor de PDR }(\%) \text { nas rações } \\
\text { Dietary RDP level }(\%)\end{array}$} & \multirow[t]{2}{*}{$\begin{array}{l}\text { Regressão } \\
\text { Regression }\end{array}$} & \multirow[t]{2}{*}{$\mathrm{CV} \%$} \\
\hline & 46 & 50 & 54 & 58 & & \\
\hline $\mathrm{g} / \mathrm{dia}$ (g/day) & 32,45 & 30,21 & 32,26 & 31,81 & $Y=31,68$ & 10,28 \\
\hline $\mathrm{g} / \mathrm{kg}^{0.75}$ & 1,07 & 1,02 & 1,10 & 1,06 & $\mathrm{Y}=1,06$ & 10,90 \\
\hline $\mathrm{g} / \mathrm{dia}(\mathrm{g} /$ day $)$ & 7,07 & 5,79 & 6,83 & 5,65 & $\mathrm{Y}=6,34$ & 14,98 \\
\hline \multirow[t]{2}{*}{$\%$ NI (\%NI) } & 22,17 & 19,44 & 21,53 & 18,28 & $Y=20,36$ & 18,28 \\
\hline & \multicolumn{4}{|c|}{$\mathrm{N}$ urina (Urinary $N$ ) } & & \\
\hline $\mathrm{g} / \mathrm{dia}(\mathrm{g} /$ day $)$ & 10,95 & 12,11 & 10,66 & 11,50 & $\mathrm{Y}=11,31$ & 26,73 \\
\hline$\% \mathrm{NI}(\% N I)$ & 34,12 & 40,21 & 32,15 & 36,28 & $\mathrm{Y}=35,70$ & 36,28 \\
\hline
\end{tabular}

PDR = proteína degradável no rúmen, \% NI: nitrogênio ingerido; BN: balanço de nitrogênio.

$R D P=$ ruminal degradable protein; \%NI: nitrogen intake; NB: nitrogen balance.

positivo sobre a digestibilidade da $\mathrm{PB}$, ainda que tenha observado maior concentração de amônia ruminal para os teores mais elevados de PDR. O autor concluiu que a perda de $\mathrm{N}$ na forma de amônia, revelada pela digestão ruminal da $\mathrm{PB}$, que variou de 4,3 a 10,5\% do total digerido, foi compensada pela ausência de efeito dos teores de PDR sobre o fluxo de PB para o duodeno.

$\mathrm{O}$ balanço de $\mathrm{N}(\mathrm{BN})$, em g/dia e porcentagem de $\mathrm{N}$ ingerido (NI) encontra-se na Tabela 5. A ingestão de N não foi influenciada pelos teores de PDR, observando-se valor médio de 31,68 g/dia. Embora os teores de PDR nas rações experimentais tenham diferido, estas rações foram isoprotéicas, o que pode explicar esses resultados. Entretanto, ao fornecerem dietas que continham diferentes teores de PB a novilhos da raça Nelore, Ladeira et al. (1999) observaram efeito linear positivo para ingestão de $\mathrm{N}$ com teor de PB crescente nas rações.

Verificou-se que a excreção do $\mathrm{N}$ via urinária foi de $35,70 \%$ do N ingerido (NI), superior à excreção nas fezes, de 20,36\% do NI. Também Lavezzo et al. (1996), ao fornecer fontes de $\mathrm{N}$ protéico (farelo de soja) e N não-protéico (uréia) em rações com $15,4 \%$ PB para ovinos, observaram maior excreção de N via urinária em relação à excreção fecal $(52,3 \%$ vs $24,4 \%$ do NI). Os autores concluíram que o menor aproveitamento do $\mathrm{N}$ retido foi consequiência do alto teor de $\mathrm{PB}$ e do excesso de amônia resultante da rápida hidrólise ruminal da uréia e da posterior absorção pela parede ruminal, aumentando a excreção de uréia na urina. Da mesma forma, 
maior excreção de $\mathrm{N}$ urinário em relação ao $\mathrm{N}$ fecal foi verificada por Bett et al. (1999) ao utilizarem farelo de soja e farelo de canola em rações para cordeiros; por Tibo et al. (2000), ao fornecerem teores crescentes de concentrado na ração; e por Prado et al. (2004), ao utilizarem teores de PDR nas rações $(47,52,57$ e $62 \%)$ e fonte de amido de alta degradabilidade ruminal para ovinos.

Todavia, Zeoula et al. (2003) forneceram a ovinos rações com 10,9\% de PB contendo diferentes teores de farinha de varredura de mandioca em substituição ao milho e farelo de soja como fonte de proteína e verificaram menor excreção de $\mathrm{N}$ via urinária $(30,9 \%$ do NI) em relação à excreção fecal (35,2\% do NI). Segundo Van Soest (1994), aumentos na ingestão de $\mathrm{N}$ estão associados à maior produção de uréia no fígado e à maior excreção de uréia via urina, enquanto o baixo teor de ingestão de $\mathrm{N}$ conduz a uma redução na excreção de uréia na urina para manutenção do pool de uréia plasmático, que está sob controle fisiológico homeostático.

Dessa forma, as razões entre o $\mathrm{N}$ excretado pelas vias urinária:fecal observadas nos trabalhos mostraram variações de 0,88 a 2,99:1, que são explicadas pelo teor de PB da ração, pela fonte de $\mathrm{N}$ utilizada, pelo teor de proteína degradável no rúmen e pela presença do carboidrato fermentável.

Como demonstrado na Tabela 5, o BN dos animais não diferiu entre os teores de PDR, sendo o valor médio do BN de $44,27 \%$ do NI, superior aos observados por Lavezzo et al. (1996), de 23,3\% do NIe por Zeoula et al. (2003), de 34,70\% do NI, para ovinos alimentados, respectivamente, com rações contendo $15,4 \%$ de $\mathrm{PB}$ e $10,9 \%$ de $\mathrm{PB}$.

Entretanto, valor de BN superior ao observado foi encontrado por Prado et al. (2004), com média de $45,7 \%$ do NI, em ovinos alimentados com $14,8 \%$ de PB e diferentes teores de PDR e farinha de varredura de mandioca como fonte de amido. O aumento de $21 \%$ na retenção de nitrogênio observado por esses autores quando os teores de PDR foram aumentados de $47 \%(40,5 \%, \%$ NI) para $62 \%$ $(51,4 \% \mathrm{NI})$ provavelmente foi ocasionado pela maior eficiência na utilização da PDR e da fonte de amido de alta degradabilidade ruminal, como reflexo da sincronização entre o N e a energia no rúmen. Segundo Van Soest (1994), a disponibilidade de carboidratos estimula o uso de amônia na síntese de aminoácidos e no crescimento microbiano. Corroborando essas observações, Zeoula et al. (2002) encontraram maior fluxo de $\mathrm{N}$ bacteriano para o duodeno e maior eficiência microbiana com a substituição total do milho pela farinha de varredura de mandioca em rações com farelo de soja para bovinos.

\section{Conclusões}

A variação nos teores de proteína degradável no rúmen, de 46 a $58 \%$, em rações com fonte de amido de baixa degradabilidade ruminal (milho) fornecidas a ovinos não alterou os coeficientes de digestibilidade aparente dos nutrientes e o balanço de nitrogênio dos animais.

\section{Literatura Citada}

ARAÚJO, G.G.L.; SILVA, J.F.C.; VALADES FILHO, S.C. et al. Efeito da degradabilidade da proteína sobre o consumo e digestão de matéria seca, matéria orgânica e carboidratos estruturais em vacas lactantes. Revista Brasileira de Zootecnia, v.24, n.3, p.371-381, 1995.

BETT, V.; SANTOS, G.T.; AROEIRA, L.J.M. et al. Desempenho e digestibilidade in vivo de cordeiros alimentados com dietas contendo canola em grão integral em diferentes formas. Revista Brasileira de Zootecnia, v.28, n.4, p.808-815, 1999.

CALDAS NETO, S.F.; ZEOULA, L.M.; PRADO, I.N. et al. Avaliação do efeito do nível de proteína degradável no rúmen em rações contendo fontes de amido de alta degradabilidade ruminal. 1. Digestibilidade in vitro. In: REUNIÃO ANUAL DA SOCIEDADE BRASILEIRA DE ZOOTECNIA, 39., 2002, Recife. Anais... Recife: Sociedade Brasileira de Zootecnia, 2002. (CD-ROM)

CALDAS NETO, S.F. Caracterização das frações protéicas dos carboidratos segundo o CNCPS e o AFRC e efeito da proteína degradável no rúmen sobre a digestibilidade e desempenho de bovinos. Maringá: Universidade Estadual de Maringá, 2004. 144p. Tese (Doutorado em Zootecnia) Universidade Estadual de Maringá, 2004.

CASPER, D.P.; SCHINGOETHE, D.J. Lactational response of dairy cows to diets varying in ruminal solubilities of carbohydrate and crude protein. Journal of Dairy Science, v.72, n.2, p.928, 1989.

FU, C.J.; FELTON, E.E.D.; LEHKUHLER, J.W. et al. Ruminal peptide concentration required to optimized microbial growth and efficiency. Journal of Dairy Science, v.79, p.13051314,2001

LADEIRA, M.M.; VALADARES FILHO, S.C.; LEÃO, M.I. et al. Concentrado, eficiência microbiana, concentração de amônia e $\mathrm{pH}$ ruminal e perdas nitrogenadas endógenas, em novilhos Nelore. Revista Brasileira de Zootecnia, v.28, n.2, p.404$311,1999$.

LAVEZZO, O.E.N.; LAVEZZO, W.; BURINI, R.C. Efeitos nutricionais da substituição parcial do farelo de soja, em dietas de ovinos. Comparação da digestibilidade aparente e balanço de nitrogênio com a cinética do metabolismo da n-glicina. Revista Brasileira de Zootecnia, v.25, n.2, p.282-297, 1996.

MARTINS, A.S.; ZEOULA, L.M.; PRADO, I.N. et al. Degradabilidade ruminal in situ da matéria seca e proteína bruta das silagens de milho e sorgo e de alguns concentrados. Revista Brasileira de Zootecnia, v.28, n.5, p.1109-1117, 1999.

McCARTHY JR., R.D.; KLUSMEYER, T.H.; VICINI, J.L. et al. Effects of source of protein and carboydrate on ruminal fermentation and passage of nutriens to the small intestine of lactating cows. Journal of Animal Science, v.70, n.8, p.20022009, 1989.

NATIONAL RESEARCH COUNCIL - NRC. Nutrient requirements of beef cattle. Washington, D.C.: National Academy of Sciences, 1985. 242p.

POORE, M.H.; MOORE, J.A.; ECK, T.P. Effect of fiber source and ruminal starch degradability on site and extent of digestion in dairy cows. Journal of Dairy Science, v.76, p.2244, 1993. 
PRADO, P.P.O. Digestibilidade dos nutrientes de rações com diferentes teores de proteína degradável no rúmen e fonte de amido de alta degradabilidade ruminal em ovinos. Maringá: Universidade Estadual de Maringá,2003. 22p. Monografia Graduação (Graduação em Zootecnia) - Universidade Estadual de Maringá, 2003.

PRADO, O.P.P.; ZEOULA, L.M.; GERON, L.J.V. et al. Balanço de nitrogênio e digestibilidade da energia bruta de rações com diferentes teores de proteína degradável no rúmen e fonte de amido de alta degradabilidade ruminal em ovinos.In: REUNIÃO ANUAL DA SOCIEDADE BRASILEIRA DE ZOOTECNIA, 41., 2004, Campo Grande. Anais... Campo Grande: Sociedade Brasileira de Zootecnia, 2004 (CD-ROM).

SILVA, J.F.; LEÃO, M.I. Fundamentos de nutrição de ruminantes. Piracicaba: Livroceres, 1979. 380p.

SILVA, D.J.; QUEIROZ, A.C. Análise de alimentos (Métodos químicos e biológicos). 3.ed. Viçosa, MG: Universidade Federal de Viçosa, 2002. 235p.

SNIFFEN, C.J.; O'CONNOR, J.D.; Van SOEST, P.J. et al. A net carbohydrate and protein system for evaluating cattle diets II. Carbohydrate and protein availability. Journal of Animal Science, v.70, n.11, p.3562-3577, 1992.

TIBO, G.C.; VALADARES FILHO, S.C.; SILVA, J.F.C. et al. Teores de concentrado em dietas de novilhos mestiços F1 Simental x Nelore. 2: Balanço nitrogenado, eficiência microbiana e parâmetros ruminais. Revista Brasileira de Zootecnia, v.29, n.3, p.921-929, 2000.

UNIVERSIDADE FEDERAL DE VIÇOSA - UFV.SAEG - Sistema de análises estatísticas e genéticas. Versão 7.1. Viçosa, MG. 1997. 150p. (Manual do usuário).
Van SOEST, P.J.; ROBERTSON, J.B.; LEWIS, B.A. Symposium: Methods for dietary fiber, neutral detergent fiber, and non starch polysaccharides in relation to animal nutrition. Journal of Animal Science, v.74, n.12, p.3583-3597, 1991.

Van SOEST, P.J. Nutritional ecology of the ruminant 2.ed. London: Comstock Publishing Associates, 1994. 476p.

ZEOULA, L.M.; MARTINS, A.S.; ALCALDE, C.R. et al. Solubilidade e degradabilidade ruminal do amido de diferentes alimentos. Revista Brasileira de Zootecnia, v.28, n.5, p.905-912, 1999.

ZEOULA, L.M.; CALDAS NETO, S.F. Recentes avanços em amido na nutrição de vacas leiteiras. In: SIMPÓSIO INTERNACIONAL EM BOVINOCULTURA DE LEITE, 2., 2001, Lavras. Anais... Lavras: Universidade Federal de Lavras, 2001. p.249-284.

ZEOULA, L.M.; CALDAS NETO, S.F.; BRANCO, A.F. et al. Mandioca e resíduo das farinheiras na alimentação de ruminantes: pH, concentração de N-NH3 e eficiência microbiana. Revista Brasileira de Zootecnia, v.31, n.3, p.1582-1593, 2002 (supl.).

ZEOULA, L.M.; CALDAS NETO, S.F.; GERON, L.J.V. et al. Substituição do milho pela farinha de varredura de mandioca (Manihot esculent, Crantz) em rações de ovinos: consumo, digestibilidade, balanços de nitrogênio e energia e parâmetros ruminais. Revista Brasileira de Zootecnia, v.32, n.2, p.491-502, 2003. 